\title{
Business Process Depicting and Analyzing with a Lightweight Approach: A Case Study
}

\author{
Yongyan Yang, Yili Yin and Jun Su \\ School of Information, Renmin University of China, Beijing 100872, P.R. China \\ thinkfly yang@hotmail.com sofia.yyl@gmail.com sujun@ruc.edu.cn
}

\begin{abstract}
When doing business process modeling and analyzing, the most frequently used methods are based on workflow technology. However, traditional workflow management systems are heavyweight and monolithic, and could not be easily reused. This paper proposes an approach of business process depicting and analyzing (BPDA). This approach decomposes the business processes into fine grains, and then finds a collection of abstracted actions (AAC), which could recompose all the processes. Main ideas and steps of the approach are introduced, and a case of a supermarket is studied to illustrate the characteristics, which are: (1) it is a lightweight approach for business process management; (2) AAC facilitates BPR; (3) the abstracted actions can turn into software component directly; (4) the abstracted actions can be easily reused.
\end{abstract}

Keywords: Business process, Case studies, Abstracted actions, Hierarchy, Polymorphism, Enumeration

\section{INTRODUCTION}

Information system engineering has changed a lot since seventies and eighties in last century. Firstly, theories and methodologies such as BPR highlight the importance of business process (BP). Secondly, fewer systems now are built from scratch and in many cases existing applications are partly used in the new system. As a result, system engineers are resorting to a more process driven approach [1].

A lot of information should be expressed when the BP is fully represented. The commonly used 5W1H (Who, What, When, Where, Why, How) shows about the aspects. Yet a process could be basically described from three dimensions, which are:

- What actions are done in the business process?

- Who do the actions?

- What the actions operate on?

In this paper the three dimensions are defined as "Action", "Role", and "Material", which are shown in Figure 5. The three dimensions are the basis of the approach of Business Process Depicting and Analyzing (BPDA). 


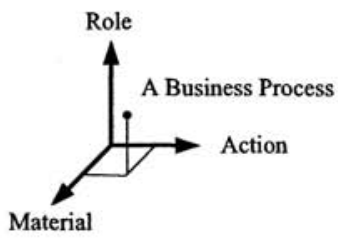

Figure 1. Three Dimensions of a Business Process

\section{THE APPROACH FOR BUSINESS PROCESS DEPICTING AND ANALYZING}

\subsection{Main Ideas}

The approach proposed in this paper partly comes from the method of activitybased modeling [2] and the idea of micro-workflow [3] in workflow technology. It is known that the representation of business processes in an enterprise is difficult because of the complexity. However, the enterprise is a hierarchical structure, and so are the business processes. Then, delaminating and decomposition could be an effective method against the complexity.

In this paper, business activities (BA) are the fundamental elements of business process. And a BA also contains the three dimensions: action, role and material. E.g. "The salesman fills in the form of sales order". Simply speaking, a business activity is completed by a single person, and with only one action (sometimes with several actions which are impartible), and operating on a single material. Mostly changing a single BA will have no effect on other BAs.

The series connection of several BAs could make up a BP, and the series connection of several BPs will make up a new BP in a higher level. Figure 2 displays the sketch map of the business process hierarchy.

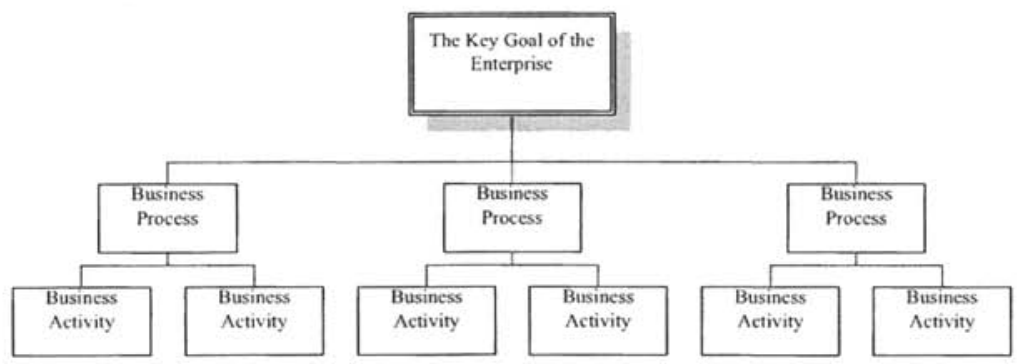

Figure 2. The Sketch Map of the Business Process Hierarchy 
There are more in the glossary of this paper, such as "Task", "Basic Task" and "Abstracted Action" (AA). A "basic task" is part of a business activity, which includes the action and material. E.g. "fill in the form of sales order". "Task" is a collection of basic tasks, or a collection of tasks in lower level which relates with each other for a particular purpose. Obviously, the concept of "task" is a variant of business process, by getting rid of the roles. Then the business processes could be constituted of two parts: the roles, and the tasks. The semantics of the glossary has been present in Figure 3, and the concept of "abstracted action" will be introduced in 2.2.4 later on.

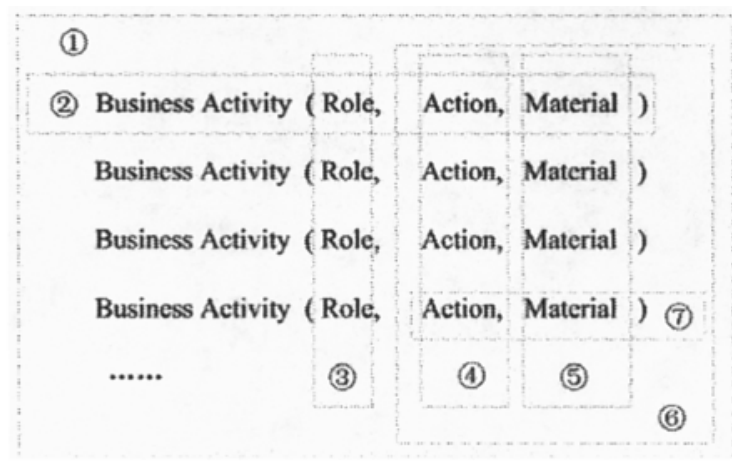

Figure 3. Semantics of the Glossary

(1)Business Process (2)Business Activity (3)the Collection of Roles (4)the Collection of Actions (5)the Collection of Materials (6)the Collection of Tasks (7)Basic Task

\subsection{Main Steps}

\subsubsection{Task Decomposition}

"Task decomposition" means to decompose the top level task into basic tasks. First identify the key goal of the enterprise (top level task), and find its main steps, which are tasks in level 2; Then for each task in level 2, find its main steps as tasks in level 3. Keep on decomposing until the basic tasks.

A main consideration in the decomposition is that "the important things are the tasks themselves, rather than the people who take responsibilities for the tasks". This helps to separate the analysis of what to do and the analysis of responsibilities, which is in favor of the role redefining, job reallocating, and further more business process reengineering.

There are some principles in task decomposition.

(1) The sub-task is a step of the parent-task, rather than "a kind of".

(2) Balance the workload in each level and in each task. Simple BP may need 3 levels, while complex BP may need 5. 


\subsubsection{Find the Roles Collection (RC)}

Roles bear the responsibilities and the authorities. There are two methods for finding the collection of roles. One comes from the histology of the enterprise, and the other takes the advantage of the procedure of task decomposition, i.e. records the corresponding role whenever a task is mentioned. Sometimes there are differences between the results of the two methods, which may hint the flaws in the personnel arrangement. For example, if a position in the enterprise never shows up in any task, it should be removed.

\subsubsection{Find the Materials Collection (MC)}

In this paper "material" means the objects which the actions operate on, such as customer order, registration form, financial report, and so on. Note that it is different from the concept of "enterprise resources", which has a much broader sense including personnel and equipments.

The material collection could be filled in at the same time as task decomposition, and be trimmed after that.

Some analysis could be done according to the task decomposition and $\mathrm{MC}$, such as life cycle analysis. Each material has its generation, state changing, and expiration.

\subsubsection{Find the Abstracted Actions Collection (AAC) from Basic Tasks}

The collection of abstracted actions could be generated after all the task decompositions are done. Abstracted action comes from the abstracting and combining of the basic tasks which have the same verb as well as similar material. For example, the tasks of "Fill in the form of sales order" and "Fill in the form of purchase order" can combine into "Fill in the bill of document". Figure 4 shows the relationship between "abstracted actions" and "basic tasks".

The concept of "abstracted action" comes from the component-based software development. It is the key to the BA reuse and BP reorganization. And it could turn into components directly when developing an operation system. Obviously, abstracted action enables BPDA to be a lightweight approach for business management.

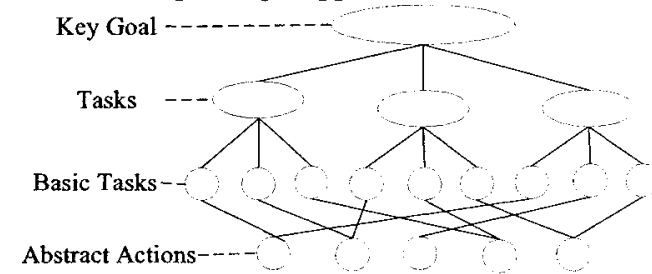

Figure 4. Abstract "Abstracted Actions" from "Basic Tasks"

However, abstracting is not enough. Note that the actions for coping with the material in different basic tasks are not exactly the same, even when the verbs are the same one. The gap needs to be handled. Here, the idea of "polymorphism" in objectoriented methodology is took advantage of. That is, to establish a processing mode for each possible material that the abstracted action could operate on. For example, when talking about the "Fill in the bill of document", we know that there should be at least 
two modes, which are "Fill in the form of sales order" and "Fill in the form of purchase order".

The significance of the abstracting and polymorphism lies on that, the level in which the changes are coped with is brought down, and that the comparatively stable factors are captured in BPDA approach.

\subsubsection{Recompose BP with Abstracted Actions, Roles, and Materials}

$\mathrm{BP}$ could be recomposed with the elements from the AAC, the $\mathrm{RC}$, and the MC. Obviously, not only original BP but also new BP could be made up by this approach.

Another consideration which corresponds to "polymorphism" is "enumeration". For example, all kinds of "Checkout" could be represented through recomposing (When necessary elements are not available in AAC, add them into AAC). Enumeration could play an important role in BP management, and will be further discusses in the case study.

\subsection{Main Documentation}

Main documents in BPDA are as follows:

- Task Decomposition List

- Role Collection

- Material Collection

- The Abstracted Actions Collection

- BP Assembly List

\section{CASE STUDY}

\subsection{Statement of the Cases}

This paper illustrates the method of BPDA by a case of a supermarket. A supermarket is a typical enterprise with business processes of purchase, sale and stock. The supermarket has these business processes:

- The supermarket gets in touch with suppliers, or suppliers contact the supermarket. The supermarket and a supplier may make an order. Then the supermarket purchases some merchandises from this supplier. The supplier or the supermarket transport merchandises to the warehouse of the supermarket.

- Customers pick merchandises and go to the cash register to check-out. Customers may choose cash or card to check-out. And if a customer wants to buy a number of merchandises, this deal may be treated as "a Large Amount Purchase". The supermarket may ask the customer to make an order in order to decide the amount and price of merchandises and the way of delivering them. 
- When warehouse or delivery, warehouse staffs will check off necessary bill of document.

\subsection{Task Decomposition}

According to 3.1, the key goal of the supermarket is to achieve the task of "Deal in the Supermarket". Therefore it becomes the jumping-off point of the analysis (That is to say, the level 1). Obviously, this task can be decomposed to three sub-tasks of "Purchase", "Management Flow of Merchandises" and "Sale" (the level 2). Now the procedure of decomposing of "Sale Merchandises" will be explained in order to illustrate the way a task is decomposed.

The purpose of decomposing "Sale Merchandises" is to gain a collection of subtasks. Tasks in this collection are steps of achieving "Sale Merchandises". According to 2.2.1, "Sale Merchandises" should be decomposed to three sub-tasks of "Propagandize Merchandises", "Make an Order" and "Check-out".

According to 3.1, one might decompose "Sale Merchandises" into "Retail" and "a Large Amount Purchase". But this kind of decomposing breaks the first principle in 2.2.1. "Retail" and "a Large Amount Purchase" are different modes of "Sale Merchandises" but not steps.

Then "Propagandize Merchandises", "Make Order" and "Check-out" is respectively decomposed until the basic tasks appear. Tasks and basic tasks of "Sale Merchandises" are shown in Figure 5.

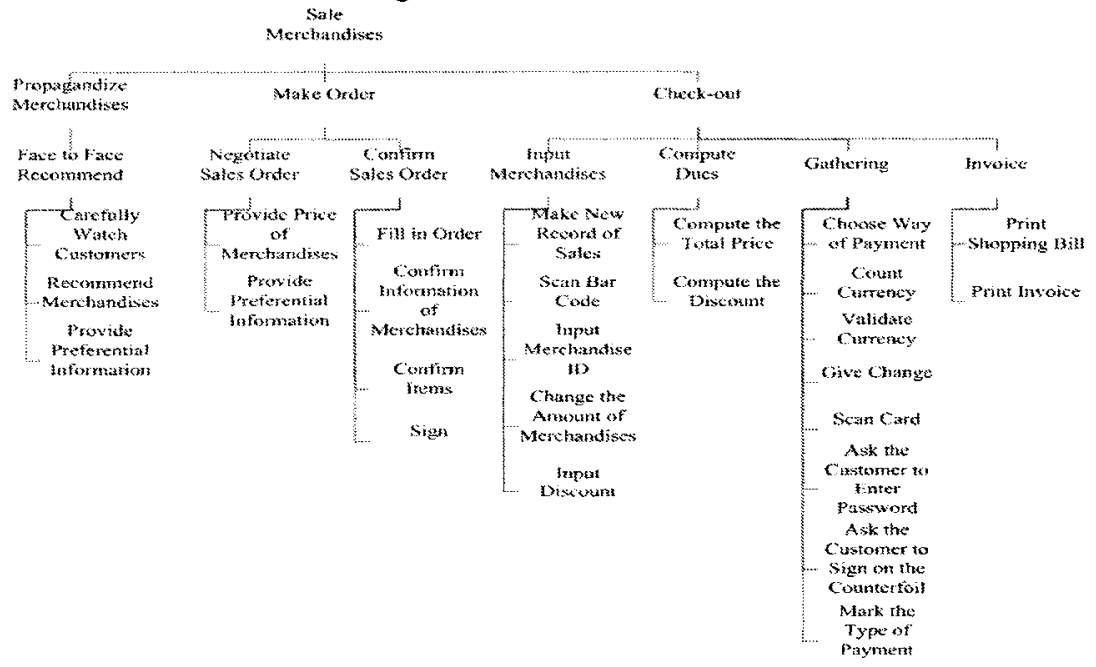

Figure 5. Decomposition of "Sale Merchandises"

Please notice that the task of "Gathering" may be implemented in way of "Pay in Cash" or "Pay by Card". "Pay by Cash" may be decomposed into "Count Currency", "Validate Currency" and "Give Change". And "Pay by Card" may be decomposed into "Scan Card", "Ask the Customer to Enter Password" and "Ask the Customer to 
Sign on the Counterfoil". And sub-tasks of these two ways of payment are all subtasks of "Gathering".

In the same way, tasks of "Purchase Merchandises" and "Management Flow of Merchandises" can be decomposed into several basic tasks.

\subsection{Find Role Collection}

According to the organization of the supermarket, we could get the roles shown in Table 1.

Table 1. Role Collection

\begin{tabular}{|l|l|l|l|}
\hline Supermarket Manager & $\begin{array}{l}\text { Logistics Department } \\
\text { Manager }\end{array}$ & $\begin{array}{l}\text { Finance } \\
\text { Department } \\
\text { Manager }\end{array}$ & $\begin{array}{l}\text { Purchase } \\
\text { Department } \\
\text { Manager }\end{array}$ \\
\hline Sales Department Manager & Stock Manager & $\begin{array}{l}\text { Cash } \\
\text { Director }\end{array}$ & $\begin{array}{l}\text { Purchase Sub- } \\
\text { Department Manager }\end{array}$ \\
\hline Sales Sub-Department Manager & Quality Checking Person & Cashier & Buyer \\
\hline Salesperson & Stock Person & & \\
\hline Tally Clerk & Transportation Director & & \\
\hline & Carrying Person & & \\
\hline
\end{tabular}

\subsection{Find Material Collection}

Materials involved in the above business processes are listed in Table 2:

Table 2. Material Collection

\begin{tabular}{|l|l|l|l|}
\hline Shopping Bill & Sales Order & $\begin{array}{l}\text { Record of } \\
\text { Inventory }\end{array}$ & Qualification \\
\hline Invoice & Purchase Order & Record of Sales & $\begin{array}{l}\text { Spoiling Reporting } \\
\text { Form }\end{array}$ \\
\hline Voucher of Card Payment & & Record of Supplier & \\
\hline
\end{tabular}

\subsection{Find the Abstracted Actions Collection}

Abstracting material in those task decomposition lists, merging similar items and deleting same items, the CAA is listed in Table 3.

Table 3. Abstracted Actions Collection

\begin{tabular}{|c|c|c|}
\hline Carefully Watch the Person & Send a Mail & Get Bill of Document \\
\hline Recommend Merchandises & Fax &  \\
\hline Provide Price & Deal with Phone Call & Check Bill of Document \\
\hline $\begin{array}{ll}\text { Provide } & \text { Preferential } \\
\text { Information } & \\
\end{array}$ & Deal with Mail & Mark Bill of Document \\
\hline Compute the Total Price & Deal with Faxes & Fill in Bill of Document \\
\hline Compute the Discount & Audit Qualification & Confirm Bill of Document \\
\hline
\end{tabular}




\begin{tabular}{|c|c|c|}
\hline Choose Way of Payment & Check Status & Print Bill of Document \\
\hline Count Currency & Count the Amount & Make New Record of Sales \\
\hline Validate Currency & Find Appropriate & Revise Record of Sales \\
\hline Give Change & $\begin{array}{l}\text { Put Merchandises into } \\
\text { Specified Position }\end{array}$ & $\begin{array}{l}\text { Make New Record of } \\
\text { Supplier }\end{array}$ \\
\hline Scan Card & Carry Merchandises & Query Record of Supplier \\
\hline Scan Code & & $\begin{array}{l}\text { Make New Record of } \\
\text { Inventory }\end{array}$ \\
\hline Virement through Bank & Picking & Revise Record of Inventory \\
\hline Pay Cash & Pack Articles & Query Record of Inventory \\
\hline Ask for Invoice & $\begin{array}{l}\text { Request Price, Quality, } \\
\text { Supplying Frequency and } \\
\text { Amount }\end{array}$ & $\begin{array}{l}\text { Record Qualification of } \\
\text { Supplier }\end{array}$ \\
\hline Ask for Signature & $\begin{array}{l}\text { Ask for Qualification of } \\
\text { Supplying }\end{array}$ & $\begin{array}{ll}\text { Record } & \text { Supplying } \\
\text { Information } & \\
\end{array}$ \\
\hline Ask for Entering Password & Sign & \\
\hline & Make a Phone Call & \\
\hline
\end{tabular}

\subsection{Use AAC, RC and MC to Recompose Business Process}

An examples are described to illustrate the way of recomposing business process by $\mathrm{AAC}, \mathrm{RC}$ and $\mathrm{MC}$, which is shown in Table 4.

Table 4. BP Assembly List: A Large Amount Purchase (Pay by Card)

\begin{tabular}{|c|c|c|c|}
\hline \multicolumn{4}{|c|}{ BP: A Large Amount Purchase (Pay by Card) } \\
\hline $\begin{array}{l}\text { Sequence } \\
\text { No. }\end{array}$ & Role & Verb from AAC & Material \\
\hline 1 & Salesperson & Carefully Watch the Person & \\
\hline 2 & Salesperson & Recommend Merchandises & \\
\hline 3 & Salesperson & Provide Price & \\
\hline 4 & $\begin{array}{l}\text { Sales Sub-Department } \\
\text { Manager }\end{array}$ & $\begin{array}{l}\text { Provide } \\
\text { Preferential Information }\end{array}$ & \\
\hline 5 & Salesperson & Fill in Bill of Document & Sales Order \\
\hline 6 & Salesperson & Confirm Bill of Document & Sales Order \\
\hline 7 & Salesperson & Sign & Sales Order \\
\hline 8 & Cashier & Make New Record of Sales & Sales Order \\
\hline 9 & Cashier & Compute the Total Price & Record of Sales \\
\hline 10 & Cashier & Compute the Discount & Record of Sales \\
\hline 11 & Cashier & Choose Way of Payment & \\
\hline 12 & Cashier & Scan Card & \\
\hline 13 & Cashier & Ask for Entering Password & \\
\hline 14 & Cashier & Ask for Signature & $\begin{array}{l}\begin{array}{l}\text { Voucher of } \\
\text { Payment }\end{array} \\
\text { Payd } \\
\end{array}$ \\
\hline 15 & Cashier & Print Bill of Document & Invoice \\
\hline
\end{tabular}


Business Process Depicting and Analyzing with a Lightweight Approach: A Case

Study 1065

\begin{tabular}{|l|l|l|l|}
\hline 16 & Cashier & Mark Bill of Document & Sales Order \\
\hline 17 & Stock Person & Check Bill of Document & Sales Order \\
\hline 18 & Stock Person & Query Record of Inventory & Record of Inventory \\
\hline 19 & Stock Person & Picking & \\
\hline 20 & Stock Person & Pack Articles & \\
\hline 21 & Carrying Person & Get Bill of Document & Sales Order \\
\hline 22 & Carrying Person & Carry Merchandises & \\
\hline 23 & Carrying Person & Make a Phone Call & \\
\hline 24 & Carrying Person & Ask for Signature & Sales Order \\
\hline 25 & Carrying Person & Give Back Bill of Document & Sales Order \\
\hline
\end{tabular}

\subsection{Recompose a New Business}

\subsubsection{Deliver from Logistic Center}

Supermarket in 3.1 only uses its own warehouse. If the supermarket now joins into a chain store system and this system has several logistic centers, the supermarket then can make use of both logistic systems. Therefore, supermarket may apply for a delivery from a logistic center. This business process is recomposed in Table 5:

Table 5. BP Assembly List: Deliver Merchandises (from Logistic Center)

\begin{tabular}{|c|c|c|c|}
\hline \multicolumn{4}{|c|}{ BP: Deliver Merchandises (from Logistic Center) } \\
\hline Sequence No. & Role & Verb from AAC & Material \\
\hline 1 & Stock Manager & Fill in Bill of Document & Application for delivery \\
\hline 2 & Stock Manager & Send Bill of Document & Application for delivery \\
\hline 3 & Logistic Center Staff & Fill in Bill of Document & Application for delivery \\
\hline 4 & Logistic Center Staff & Answer Bill of Document & Application for delivery \\
\hline 5 & Stock Manager & Send Bill of Document & Sales Order \\
\hline 6 & Logistic Center Staff & Query Record of Inventory & Record of Inventory \\
\hline 7 & Logistic Center Staff & Picking & \\
\hline 8 & Logistic Center Staff & Pack Articles & \\
\hline 9 & $\begin{array}{l}\text { Logistic Center Carrying } \\
\text { Person }\end{array}$ & Get Bill of Document & Sales Order \\
\hline 10 & $\begin{array}{l}\text { Logistic Center Carrying } \\
\text { Person }\end{array}$ & Carry Merchandises & \\
\hline 11 & $\begin{array}{l}\text { Logistic Center Carrying } \\
\text { Person }\end{array}$ & Make a Phone Call & \\
\hline 12 & $\begin{array}{l}\text { Logistic Center Carrying } \\
\text { Person }\end{array}$ & Ask for Signature & Sales Order \\
\hline 13 & $\begin{array}{l}\text { Logistic Center Carrying } \\
\text { Person }\end{array}$ & Give Back Bill of Document & Sales Order \\
\hline
\end{tabular}




\subsubsection{The Expansion of $\mathrm{AAC}$}

From the above tables we can see that two new abstracted actions appear: "Send Bill of Document" and "Answer Bill of Document". Therefore the recomposing of the new business process needs to supplement these two abstracted actions into the primary AAC.

\subsection{Enumeration, Levels and Stability}

In the view of business, business processes of "Retail" and "a Large Amount Purchase" are two kinds of ways of the same business, so do the processes of "Deliver from supermarket" and "deliver from logistic center". Generally, when there are several ways of one business in an enterprise, they can be enumerated one by one.

From the case study we can see that in the hierarchical structure of business processes, the higher the level, the more stable the content it describes. For example, the goal of the supermarket and the business processes of "Purchase", "Management Flow of Merchandises" and "Sale" are very stable. And the lower the level, the more possible the content changes.

This paper makes use of Abstracted Actions Collection, and then points out that one should enumerate all of the methods involved in AAC when doing system development. Enumeration can be considered as a measure of dealing with changes. Making use of enumeration may put levels impacted by changes lower. This highly reduces the impacts on business processes.

This also explains why we didn't decompose "Sale Merchandises" into "Retail" and "a Large Amount Purchase". This way of decomposition means to enumerate business processes in a high level and enlarges the unstable factors.

\section{CONCLUSIONS}

This paper proposes an approach of business process depicting and analyzing, which separates the three important dimensions and decompose them into fine grains. There are several characteristics:

- Delaminating reduces the complexity;

- $\mathrm{AAC}$ enables the $\mathrm{BA}$ reusing and $\mathrm{BP}$ reorganizing;

- Elements in AAC corresponds to components

- Deal with changes with polymorphism and enumeration, and reduce the effect that changes bring in;

- The approach is lightweight.

Nevertheless, this approach is far from perfect. The procedure of task decomposition is not standard, and more information are not present (such as when, where and so on). Further researches will be done to refine the approach. 
Business Process Depicting and Analyzing with a Lightweight Approach: A Case

\section{REFERENCES}

1. W.V. Aalst, A.T. Hofstede, and M. Weske, Business Process Management: A Survey. BPM2003, LNCS2678 (2003), pp.1-12.

2. Y. Fan, Fundamentals of Workflow Management Technology (Tsinghua University Publisher, 2001).

3. D.A. Manolescu and R.E. Johnson. A Micro-Workflow Framework for Compositional Object-Oriented Software Development, OOPSLA'99 workshop on the Implementation and Application of Object-Oriented Workflow Management (1999).

4. F. Leymann, D. Roller, and M.T. Schmidt, Web services and business process management, IBM Systems Journal. Volume 41, Number 2, pp.198-211, (2002). 